\title{
Simplifying Laparoscopic Surgery for Left Side Colon and Rectal Cancer Using Linear Stapler for Vascular Ligation: A Prospective Cohort Study
}

\author{
Masanori Naito, Takeo Sato, Takatoshi Nakamura, Takahiro Yamanashi, Hirohisa Miura, \\ Atsuko Tsutsui, Masahiko Watanabe*
}

Department of Surgery, School of Medicine, Kitasato University, Sagamihara, Japan

Email: *mnaito @kitasato-u.ac.jp

How to cite this paper: Naito, M., Sato, T., Nakamura, T., Yamanashi, T., Miura, H., Tsutsui, A. and Watanabe, M. (2017) Simplifying Laparoscopic Surgery for Left Side Colon and Rectal Cancer Using Linear Stapler for Vascular Ligation: A Prospective Cohort Study. Journal of Cancer Therapy, 8, 341-348

https://doi.org/10.4236/jct.2017.84030

Received: March 15, 2017

Accepted: April 25, 2017

Published: April 28, 2017

Copyright (c) 2017 by authors and Scientific Research Publishing Inc. This work is licensed under the Creative Commons Attribution International License (CC BY 4.0).

http://creativecommons.org/licenses/by/4.0/

\begin{abstract}
Introduction: Systematic lymphadenectomy and ligation of the feeding artery is extremely important when performing radical resection in colorectal cancer. However, vascular surgery via laparoscopy requires advanced skills and techniques; thus, this procedure needs to be simplified while maintaining quality of the surgery to make it a preferred technique for the surgeons. Methods: There were 49 patients who underwent laparoscopic sigmoidectomy or anterior resection till T2 level for sigmoid colon cancer and recto-sigmoid colon cancer. We analyzed short-term and long-term outcomes between stapling ligation and clipping ligation techniques used in these surgeries. Results: The mean volume of blood loss in the stapling ligation group was $12.8 \pm 12.3 \mathrm{ml}$, which was significantly lower than $41.9 \pm 71.2 \mathrm{ml}$ of mean volume of blood loss in the clipping ligation group. There was no significant difference in the mean duration of surgery, the mean number of harvested lymph nodes, morbidity, recurrence, and 5-year relapse free survival rates between the 2 groups. Conclusions: This study demonstrates a surgical technique using staplers for vascular treatment of tumor-feeding arteries as a new technical improvement in laparoscopic colectomy for the treatment of early-stage colon cancer. We found that the described procedure was technically safe, simple, convenient, and oncologically valid.
\end{abstract}

\section{Keywords}

Laparoscopic Surgery, Colorectal Cancer, Vascular Ligation, Linear Stapler 


\section{Introduction}

Since Jacobs et al. reported the first laparoscopic colectomy in 1991 [1], it has become popular as a minimally invasive surgical technique that offers excellent cosmetic results. In recent years, this technique has been used in rectal resection for rectal cancer, and is likely to become even more widely used in the future. The greatest advantage of laparoscopic surgery is that it is minimally invasive. The small size of the surgical incision has led to improvements in the cosmetic aspects of the surgery and reduced wound pain. Furthermore, intestinal peristalsis is maintained during the surgery; thus, the technique also offers great advantages such as early ambulation and a shorter period to initiate oral intake of food and water [2] [3] [4] [5] [6]. Additionally, the added magnification of endoscopes has facilitated better understanding of microscopic blood vessels and nerves. Thus, it has enabled reduction in the amount of blood loss and increase in nerve preservation.

Systematic lymphadenectomy through ligation of the feeding artery is extremely important when performing radical resection in colorectal cancer. However, vascular surgery via laparoscopy requires advanced skills and techniques; thus, this procedure needs to be simplified while maintaining quality of the surgery to make it a preferred technique for the surgeons. In laparoscopic surgery for colorectal cancer, there are no reports of long and short-term outcomes on vascular ligation using linear stapler. To simplify the procedure of laparoscopic surgical treatment of early-stage colorectal cancer, we used surgical staplers to perform vascular reconstruction during lymphadenectomy. We analyzed if this surgical method was technically safe and valid from an oncological viewpoint in this study.

\section{Materials and Methods}

\subsection{Data Source}

This study included 49 patients with sigmoid colon and recto-sigmoid colon cancer who had been selected from a list of patients with early-stage colorectal cancer (until T2 level). These patients had undergone laparoscopic radical colectomy with D2 lymphadenectomy in accordance with the Guidelines for the Treatment of Colon Cancer in Japan [7] at Kitasato University (Sagamihara, Japan) between January 2006 and December 2011. According to the vascular reconstruction method performed during lymphadenectomy, they were categorized into 2 groups. In one group, linear stapler was used (stapling ligation), while in the other, clips were used (clipping ligation). The stapling ligation was used in 35 patients (20 underwent sigmoidectomy and 15 underwent anterior resection) and clipping ligation was used in 14 patients (10 underwent sigmoidectomy and 4 underwent anterior resection) (Table 1). Blood loss, duration of surgery, number of harvested lymph nodes, morbidity, recurrence, and five-year relapse-free survival, were obtained from the medical records and analyzed in detail. 


\subsection{Surgical Technique}

In vascular reconstruction using staplers, detachment and mobilization of the mesocolon using the internal approach was performed and was followed by an incision in the avascular area of the mesocolon. Following this, the mesentery was opened, a stapler was inserted, and superior rectal artery, inferior mesenteric vein, and adipose tissue of the mesocolon were ligated and detached (Figure $1(\mathrm{a})$ ). The avascular area of the mesocolon was identified as an area between proximal left colic artery and the marginal vessels, lateral to the superior rectal artery (Figure 1(b)). Endo GIA ${ }^{\mathrm{mm}}$ Tri-Staple ${ }^{\mathrm{mm}}$ Technology $45-\mathrm{mm}$ Grey cartridge (Medtronic, Minneapolis, MN) was used as the surgical stapler.

In vascular reconstruction using clips, the same technique was used for the separation and mobilization of the mesocolon. Identification and exposure of the avascular area were followed by double-clipping for vascular reconstruction. Ligation and separation were performed to complete the vascular reconstruction of the procedure.

\subsection{Statistical Analysis}

Statistical analysis was performed using JMP version 11.0.2 (SAS Institute). Mann-Whitney U test was used to analyze differences between stapling ligation

Table 1. Patient characteristics.

\begin{tabular}{cccc}
\hline & $\begin{array}{c}\text { Stapling } \\
\mathrm{n}=35\end{array}$ & $\begin{array}{c}\text { Clipping } \\
\mathrm{n}=14\end{array}$ & $p$ \\
\hline Mean age (years \pm SD) & $64.4 \pm 10.3$ & $65.7 \pm 11.2$ & 0.58 \\
Gender Male/Female & $16 / 19$ & $9 / 5$ & 0.29 \\
Procedure & $20 / 15$ & $10 / 4$ & 0.41 \\
Sigmoidectomy/Anterior resection & $30 / 5$ & $10 / 4$ & 0.22 \\
pT factor <T2/T2 & $32 / 3$ & $14 / 0$ & 0.20 \\
pN factor N0/N1 & $73.2(41.9-108.8)$ & $69.5(32.3-108.7)$ & 0.98 \\
Median follow-up times \\
(months, range)
\end{tabular}

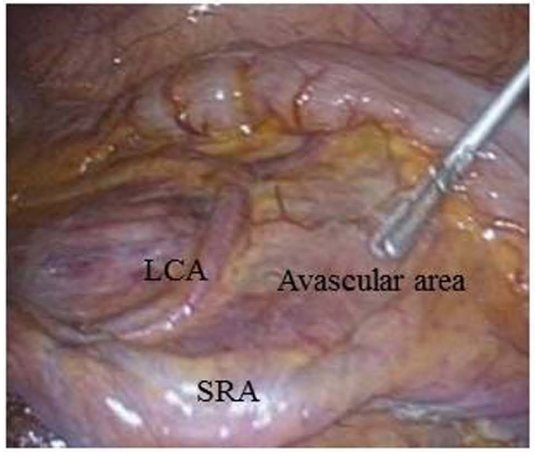

(a)

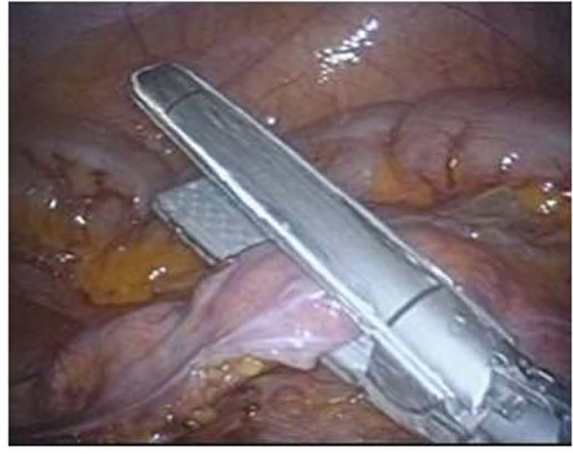

(b)

Figure 1. Vascular pedicle ligation technique. After mobilizing from retroperitoneum with medial approach, we opened the avascular area of mesenterium (a) and ligated the vascular pedicle with a linear stapler (b). LCA: left colic artery, SRA: superior rectal artery. 
and clipping ligation techniques, and a p-value $<0.05$ was considered to indicate statistical significance.

\subsection{Ethical Statements}

All patients were given detailed explanation and informed written consents were obtained in accordance with the guidelines of the Declaration of Helsinki.

\section{Results}

In stapling ligation group, the mean age of patients (males, 16; females, 19) was $64.4 \pm 10.3$ years, and the median follow-up period was 73.2 (range, 41.9 - 108.8) months (Table 1). The mean age of patients (males, 9; females, 5) in clipping ligation group was $65.7 \pm 11.2$ years, and the median follow-up period was 69.5 (range, 32.3 - 108.7) months (Table 1).

The mean duration of surgery was $203.6 \pm 47.6 \mathrm{~min}$ in the stapling ligation group and $220.5 \pm 51.5 \mathrm{~min}$ in the clipping ligation group. The mean volume of blood loss in the stapling ligation group was $12.8 \pm 12.3 \mathrm{ml}$, which was significantly lower than $41.9 \pm 71.2 \mathrm{ml}$ lost in the clipping ligation group (Table 2). There was no significant difference in the mean number of harvested lymph nodes, morbidity, and recurrence between the 2 groups (Table 2). Five-year relapse free survival rate was $95.2 \%$ in stapling ligation group and $100 \%$ in clipping ligation group (Figure 2, $p=0.5479$ ).

\section{Discussion}

Based on the findings of previous randomized controlled studies, a consensus has been reached regarding the efficacy and safety of laparoscopic colectomy in the treatment of early-stage colon cancer [3] [8] [9] [10] [11]. Additionally, compared with open surgery, laparoscopic surgery has been enormously beneficial to the quality of life of patients because of the reduced postoperative pain, low risk of developing a postoperative ileus, and shorter postoperative hospital stay [2] [3] [4] [5] [6]. In radical treatment of colorectal cancer, the main feeding artery needs to be ligated proximally, along with resection of the lymph nodes thereof [12] [13] [14] [15]. In recent years, lymphadenectomy with preservation

Table 2. Short-term and long-term outcomes.

\begin{tabular}{cccc}
\hline & $\begin{array}{c}\text { Stapling } \\
\mathrm{n}=35\end{array}$ & $\begin{array}{c}\text { Clipping } \\
\mathrm{n}=14\end{array}$ & $p$ \\
\hline Operation time (min.) & $203.6 \pm 47.6$ & $220.5 \pm 51.5$ & 0.29 \\
Blood loss (ml) & $12.8 \pm 12.3$ & $41.9 \pm 71.2$ & 0.02 \\
Harvested lymph node (number) & $10.9 \pm 7.4$ & $10.6 \pm 7.0$ & 0.92 \\
$\begin{array}{c}\text { Recurrence } \\
\text { (rate, \%) }\end{array}$ & 1 & 0 & 0.55 \\
$\begin{array}{c}\text { Morbidity } \\
\text { (rate, \%) }\end{array}$ & $(2.9 \%)$ & $(0.0 \%)$ & \\
\hline
\end{tabular}

Morbidity; Clavien-Dindo classification Grade III $\leq$. 


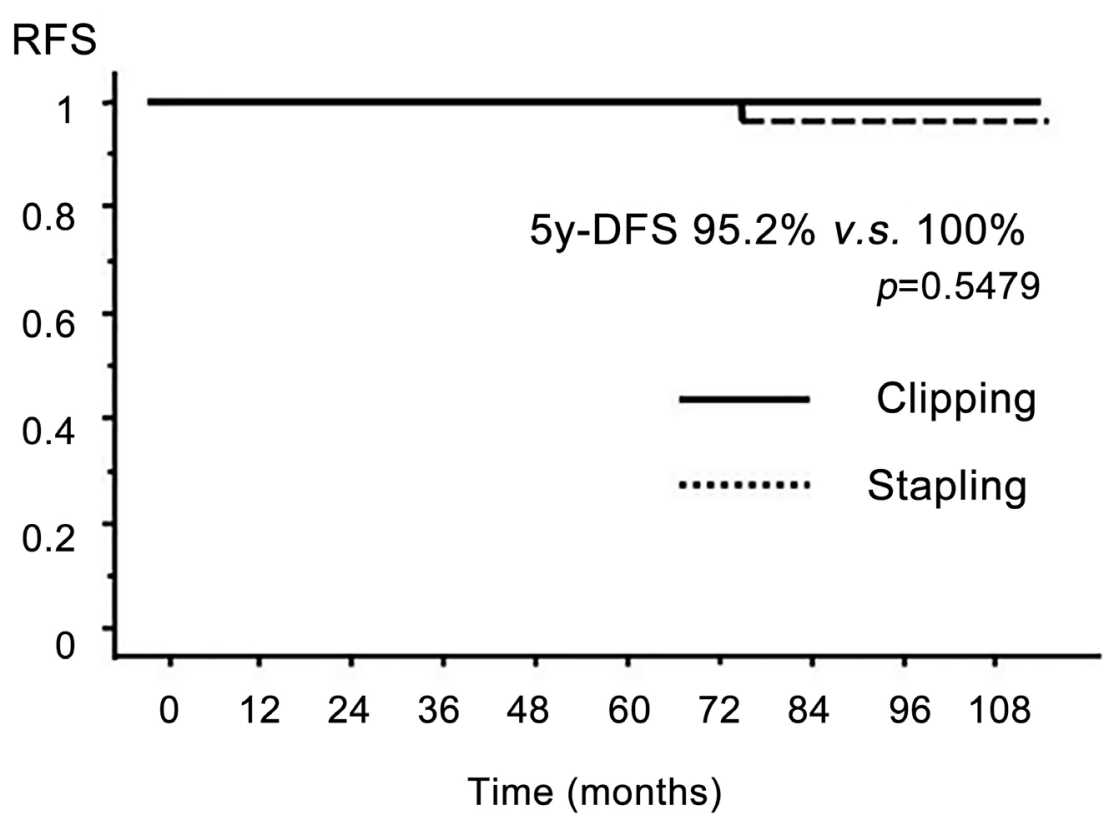

Figure 2. The 5-year relapse-free survival (RFS). There were no significant differences between the clipping ligation and stapling ligation group.

of the colic artery in laparoscopic surgical treatment of sigmoid and rectal cancers has been reported [16]. However, considerable training is required before a surgeon can perform this highly skill-intensive surgery. Thus, to further improvise laparoscopic surgery in colorectal cancers, it is important to make devise new surgical techniques that are technically simple and oncologically safe.

Guidelines pertaining to the treatment of colon cancers published by the Japan Society for Cancer of the Colon and Rectum specify the ranges of lymphadenectomy to be performed depending on the depth of tumor infiltration in the intestinal wall and the extent of lymph node metastasis. According to the guidelines, D2 lymphadenectomy, which is indicated for early-stage cancers (up to the stage of cT2N0), should be combined with resection of tumor-specific lymph nodes located around the feeding artery (known as intermediate lymph nodes). In right-side colon cancers such as cecal cancer and ascending colon cancer, this is achieved through ligation and resection of the ileocolic artery and right colic artery. In contrast, in left-side colon cancers and rectal cancers, such as sigmoid cancer and rectosigmoid junction cancer, it is achieved through ligation and resection of the sigmoid artery and rectal artery after bifurcation of the left colic artery [7]. In both cases, each artery needs to be exposed and each branch confirmed, following which they are ligated using clips and resected. Thus, there is a risk of bleeding due to the sheathing of blood vessels and due to damage to the vascular wall. Additionally, strenuous effort is required for this procedure. Kobayashi et al. [17] previously reported that the mean time required to perform a D2 lymphadenectomy was $36.2 \mathrm{~min}$ and that the procedure took a long time to perform because of its complexity. Therefore, in this study, which was aimed at simplifying the surgical technique used in laparoscopic surgery for early-stage 
colon cancers, stapler ligation was used to perform vascular reconstruction during lymphadenectomy, and its adequacy was examined.

The results revealed that there was no significant difference in the duration of the surgery between the stapling ligation group and clipping ligation group. We believe the absence of difference was because tasks, other than vascular reconstruction, are time consuming.

However, blood loss was significantly lesser in the stapling ligation group than in the clipping ligation group, which we believe was because of the complexity of the branching of blood vessels in the left side of colon. In other words, in clipping ligation, considerable blood loss was thought to have resulted from procedures aimed at exposing complex vascular branches and treating the mesenteric adipose tissue whereas in stapling ligation, the mesenteric adipose tissue and blood vessels were ligated and dissected in bulk, which reduced the associated bleeding.

No apparent differences were observed in the number of harvested lymph nodes, morbidity, recurrence, and 5-year relapse free survival rates between the 2 groups. These findings suggest that the procedure described in this study was valid from, both, oncological and technical viewpoints.

Since this study is a retrospective study in a single center and the number of cases is small, there is a limit to describing validity and safety. However, the stapling ligation technique is a simple and useful procedure, it is expected that prospective randomized control trial will be conducted to demonstrate validity and safety.

\section{Conclusion}

This study demonstrates a surgical technique using staplers for the vascular treatment of tumor-feeding arteries as a technical improvement in laparoscopic colectomy for the treatment of early-stage colon cancer. Additionally, we found that the described procedure was technically safe, simple, convenient, and oncologically valid. In the future, this procedure may potentially contribute to an increase in laparoscopic colectomy for the treatment of colon cancers.

\section{Conflict of Interests}

The authors declare that they have no conflict of interests.

\section{Authors' Contributions}

Masanori Naito: designed the study, performed the procedures, collected data, and composed the manuscript.

Masahiko Watanabe: reviewed the manuscript.

Hirohisa Miura, Takatoshi Nakamura, Takeo Sato, Takahiro Yamanashi and Atsuko Tsutsui: performed procedures.

\section{References}

[1] Jacobs, M., Verdeja, J.C. and Goldstein, H.S. (1991) Minimally Invasive Colon Re- 
section (Laparoscopic Colectomy). Surgical Laparoscopy Endoscopy \& Percutaneous Techniques, 1, 144-150.

[2] Wexner, S.D., Cohen, S.M., Johansen, O.B., Nogueras, J.J. and Jagelman, D.G. (1993) Laparoscopic Colorectal Surgery: A Prospective Assessment and Current Perspective. British Journal of Surgery, 80, 1602-1605.

https://doi.org/10.1002/bjs.1800801238

[3] Lacy, A.M., Garcia-Valdecasas, J.C., Delgado, S., Castells, A., Taura, P., Pique, J.M. and Visa, J. (2002) Laparoscopy-Assisted Colectomy versus Open Colectomy for Treatment of Non-Metastatic Colon Cancer: A Randomised Trial. The Lancet, 359, 2224-2229. https://doi.org/10.1016/S0140-6736(02)09290-5

[4] Milson, J.W., Bohm, B., Hammerhofer, K.A., Fazio, V., Steiger, E. and Elson, P. (1998) A Prospective Randomised Trial Comparing Laparoscopic versus Conventional Techniques in Colorectal Cancer Surgery: A Preliminary Report. Journal of the American College of Surgeons, 187, 46-54.

https://doi.org/10.1016/S1072-7515(98)00132-X

[5] Guillou, P.J., Quirke, P., Thorpe, H., Walker, J., Jayne, D.G., Smith, A.M., Heath, R.M. and Brown, J.M., MRC CLASICC Trial Group (2005) Short-Term Endopoints of Conventional versus Laparoscopic-Assisted Surgery in Patients with Colorectal Cancer (MRC CLASICC Trial): Multicentre Randomised Controlled Trial. The Lancet, 365, 1718-1726. https://doi.org/10.1016/S0140-6736(05)66545-2

[6] Clinical Outcomes of Surgical Therapy Study Group (2004) A Comparison of Laparoscopically Assisted and Open Colectomy for Colon Cancer. The New England Journal of Medicine, 350, 2050-2059. https://doi.org/10.1056/NEJMoa032651

[7] Japanese Society for Cancer of the Colon and Rectum (2010) JSCCR Guidelines 2010 for the Treatment of Colorectal Cancer. Kanehara \& Co. Ltd., Tokyo.

[8] Fleshman, J., Sargent, D.J., Green, E., Anvari, M., Stryker, S.J., Beart Jr., R.W., Hellinger, M., Flanagan Jr., R., Peters, W. and Nelson, H., Clinical Outcomes of Surgical Therapy Study Group (2007) Laparoscopic Colectomy for Cancer Is Not Inferior to Open Surgery Based on 5-Year Data from the COST Study Group Trial. Annals of Surgery, 246, 662-664. https://doi.org/10.1097/sla.0b013e318155a762

[9] Colon Cancer Laparoscopic or Open Resection Study Group (2009) Survival after Laparoscopic Surgery versus Open Surgery for Colon Cancer: Long-Term Outcome of Randomized Clinical Trial. Lancet Oncology, 10, 44-52.

[10] Jayne, D.V., Guillou, P.J., Thorpe, H., Quirke, P., Copeland, J., Smith, A.M., Heath, R.M. and Brown, J.M. (2007) Randomized Trial of Laparoscopic-Assisted Resection of Colorectal Carcinoma: 3-Year Results of the UK MRC CLASICC Trial Group. Journal of Clinical Oncology, 25, 3061-3068. https://doi.org/10.1200/JCO.2006.09.7758

[11] Leung, K.L., Kwok, S.P., Lam, S.C., Lee, J.F., Yiu, R.Y., Ng, S.S., Lai, P.B. and Lau, X.Y. (2004) Laparoscopic Resection of Rectosigmoid Carcinoma: Prospective Randomized Trial. The Lancet, 363, 1187-1192. https://doi.org/10.1016/S0140-6736(04)15947-3

[12] Titu, L.V., Tweedle, E. and Rooney, P.S. (2008) High Tie of the Inferior Mesenteric Artery in Curative Surgery for Left Colonic and Rectal Cancer: A Systematic Review. Digestive Surgery, 25, 148-157. https://doi.org/10.1159/000128172

[13] West, N.P., Hohenberger, W., Weber, K., Perrakis, A., Finan, P.J. and Quirke, P. (2010) Complete Mesocolic Excision with Central Vascular Ligation Produces an Oncologically Superior Specimen Compared with Standard Surgery for Carcinoma of the Colon. Journal of Clinical Oncology, 28, 272-278.

https://doi.org/10.1200/JCO.2009.24.1448 
[14] Kanemitsu, Y., Hirai, T., Komori, K. and Kato, T. (2006) Survival Benefit of High Ligation of the Inferior Mesenteric Artery in Sigmoid Colon or Rectal Cancer Surgery. British Journal of Surgery, 93, 609-615. https://doi.org/10.1002/bjs.5327

[15] Chin, C.C., Yeh, C.Y., Tang, R., Changchien, C.R., Huang, W.S. and Wang, J.Y. (2008) The Oncologic Benefit of High Ligation of the Inferior Mesenteric Artery in the Surgical Treatment of Rectal or Sigmoid Colon Cancer. International Journal of Colorectal Disease, 23, 783-788. https://doi.org/10.1007/s00384-008-0465-5

[16] Sekimoto, M., Takemasa, I., Mizushima, T., Ikeda, M., Yamamoto, H., Doki, Y. and Mori, M. (2011) Laparoscopic Lymph Node Dissection around the Inferior Mesenteric Artery with Preservation of the Left Colic Artery. Surgical Endoscopy, 25, 861-866. https://doi.org/10.1007/s00464-010-1284-7

[17] Kobayashi, M., Okamoto, K., Namikawa, T., Okabayashi, T. and Araki, K. (2006) Laparoscopic Lymph Node Dissection around the Inferior Mesenteric Artery for Cancer in the Lower Sigmoid Colon and Rectum: Is D3 Lymph Node Dissection with Preservation of the Left Colic Artery Feasible? Surgical Endoscopy and Other Interventional Techniques, 20, 563-569. https://doi.org/10.1007/s00464-005-0160-3

Submit or recommend next manuscript to SCIRP and we will provide best service for you:

Accepting pre-submission inquiries through Email, Facebook, LinkedIn, Twitter, etc. A wide selection of journals (inclusive of 9 subjects, more than 200 journals)

Providing 24-hour high-quality service

User-friendly online submission system

Fair and swift peer-review system

Efficient typesetting and proofreading procedure

Display of the result of downloads and visits, as well as the number of cited articles

Maximum dissemination of your research work

Submit your manuscript at: http://papersubmission.scirp.org/

Or contact jct@scirp.org 